\title{
3) General anaesthesia versus local anaesthesia for carotid surgery (GALA): a multicentre, randomised controlled trial
}

GALA Trial Collaborative Group*

\section{Summary}

Lancet 2008; 372: 2132-42

Published Online

November 27, 2008

DOI:10.1016/50140-

6736(08)61699-2

See Comment page 2092

*Members listed at end of paper

Correspondence to:

Dr Steff C Lewis, Neurosciences

Trials Unit, Division of Clinical Neurosciences, Western General Hospital, Crewe Road, Edinburgh EH4 2XU, UK steff.lewis@ed.ac.uk

Background The effect of carotid endarterectomy in lowering the risk of stroke ipsilateral to severe atherosclerotic carotid-artery stenosis is offset by complications during or soon after surgery. We compared surgery under general anaesthesia with that under local anaesthesia because prediction and avoidance of perioperative strokes might be easier under local anaesthesia than under general anaesthesia.

Methods We undertook a parallel group, multicentre, randomised controlled trial of 3526 patients with symptomatic or asymptomatic carotid stenosis from 95 centres in 24 countries. Participants were randomly assigned to surgery under general $(n=1753)$ or local $(n=1773)$ anaesthesia between June, 1999 and October, 2007. The primary outcome was the proportion of patients with stroke (including retinal infarction), myocardial infarction, or death between randomisation and 30 days after surgery. Analysis was by intention to treat. The trial is registered with Current Control Trials number ISRCTN00525237.

Findings A primary outcome occurred in $84(4.8 \%)$ patients assigned to surgery under general anaesthesia and $80(4.5 \%)$ of those assigned to surgery under local anaesthesia; three events per 1000 treated were prevented with local anaesthesia (95\% CI -11 to 17; risk ratio [RR] 0.94 [95\% CI 0.70 to 1.27$])$. The two groups did not significantly differ for quality of life, length of hospital stay, or the primary outcome in the prespecified subgroups of age, contralateral carotid occlusion, and baseline surgical risk.

Interpretation We have not shown a definite difference in outcomes between general and local anaesthesia for carotid surgery. The anaesthetist and surgeon, in consultation with the patient, should decide which anaesthetic technique to use on an individual basis.

Funding The Health Foundation (UK) and European Society of Vascular Surgery.

Introduction

Patients with severe atherosclerotic stenosis at the internal carotid-artery origin have a high risk of ipsilateral ischaemic stroke. On the basis of previous randomised trials, ${ }^{1}$ carotid endarterectomy is often advised, particularly after an ipsilateral transient ischaemic attack or non-disabling ischaemic stroke. ${ }^{2}$ There is less benefit for asymptomatic carotid stenosis. ${ }^{3}$ Several complications may take place during or soon after carotid endarterectomy, including stroke in $5-7 \%$ of cases. ${ }^{4}$ Operative practices under local (or regional) anaesthesia may be safer than under general anaesthesia, partly because awake testing of brain function under local anaesthesia during carotid clamping alerts the surgeon to the need for a shunt more reliably than the various indirect techniques used under general anaesthesia. Consequently, fewer shunts are used. Although shunts should protect the brain from stroke that results from low cerebral-blood flow during carotid clamping, they can damage the arterial wall causing embolism to the brain.

Some randomised trials of carotid endarterectomy, ${ }^{5}$ and spinal and epidural anaesthesia for other types of surgery, ${ }^{6}$ have suggested more benefits of local than of general anaesthesia. However, sample sizes were often small in these studies, and some analyses combined different types of patients and procedures. Also, some studies were confounded by the use of regional anaesthesia as an adjunct to general anaesthesia. We have therefore undertaken a large randomised trial of general versus local anaesthesia for carotid endarterectomy.

\section{Methods}

Participants

We enrolled 3526 patients from 95 centres in 24 countries. Patients with symptomatic or asymptomatic internal carotid stenosis for whom open surgery with either local or general anaesthesia was advised were eligible. The planned sample size was 5000 patients, on the basis of a predicted one-third reduction in risk of a primary outcome under local compared with general anaesthesia (from $7.5 \%$ to $5 \%$ ); this is a more-conservative treatment effect than suggested by the Cochrane meta-analysis. ${ }^{5}$

Exclusion criteria included a simultaneous bilateral carotid endarterectomy; carotid endarterectomy combined with another operative procedure such as coronary-artery bypass surgery; or if patients had previously taken part in the trial. The study was approved by the Northern and Yorkshire Multicentre Research Ethics Committee. All patients gave written informed consent. 


\section{Study design}

This was a two-arm, parallel group, multicentre randomised controlled trial of general anaesthesia versus local anaesthesia for carotid surgery (GALA). We published complete information of the study protocol elsewhere.?

Each consultant surgeon in the trial centres had to have done at least 15 carotid endarterectomy procedures per year with either general or local anaesthesia. The proportion of trainees-both surgical and anaestheticwas balanced as much as possible between the two groups. Shunts were to be used in patients who underwent surgery with local anaesthesia when awake testing indicated a need. Otherwise, we allowed centres to provide general or local anaesthesia and surgery according to routine practice, and we obtained relevant information for each technique.

For every patient, the local collaborator obtained baseline data, which were sent to the trial office in Edinburgh by fax, telephone, or web interface. The office randomised patients to surgery under either general or local anaesthesia, stratified by centre and with balanced blocks of variable size, ensuring that allocation was completely concealed before the decision to randomise a patient and after baseline data were received.

We could not blind patients or the surgical team to the randomised treatment allocation. However, the independent stroke physician or neurologist who saw patients 1 month after surgery was unaware of the type of anaesthesia that the patient had received, although this blinding could be broken by the patient or by looking at hospital notes. The independent stroke physician or neurologist examined the following outcomes: stroke (including retinal infarction), myocardial infarction, death (and cause), transient ischaemic attack, and other complications after surgery. Stroke severity was assessed by the modified Rankin scale 6 months after onset by post to the patient's family doctor (or other appropriate physician).

For all possible reported primary outcomes, the trial office requested information from hospital notes, death certificates, or family-doctor records where appropriate. Enquiry was made to ensure any reported transient ischaemic attack was not a minor stroke, with the usual 24-h cut-off between stroke and transient ischaemic attack, without accounting for any hypodensity on brain imaging. Myocardial infarction and other coronary events were defined from clinical history, electrocardiograph, and cardiac enzymes. A neurologist (CPW), unaware of treatment allocation, then prepared a summary for every patient that, depending on the outcome, was audited by an independent neurologist (PMR) or cardiologist (APB), who were also unaware of treatment allocation.

Data were analysed by the trial statistician (SCL) and reviewed annually in strict confidence by the Data Monitoring Committee. Everyone else involved in the study was unaware of the treatment allocation until the database was locked. The trial was not stopped early; indeed, we continued randomisation for 1 year after the end of the planned recruitment period. In this way, we had less follow-up information on secondary outcomes at 1 year after surgery in patients randomised during the last year of the trial (417 under general anaesthesia and 428 under local anaesthesia), but a larger sample size for the 30-day primary outcome.

\section{Outcome measures}

The primary outcome was the proportion of patients with stroke (including retinal infarction), myocardial infarction, or death between randomisation and 30 days after anaesthesia (or 30 days after randomisation for the few patients for whom surgery was scheduled but not done). We examined various secondary outcomes: survival free of stroke, myocardial infarction, or death up to 1 year after anaesthesia; length of stay in recovery, highdependency units, intensive-therapy units, and overall in hospital; and, in patients in UK, health-related quality of life at about 30 days after anaesthesia with the short form (SF)-36 and EuroQoL.

Outcome data were obtained by the surgical or anaesthetic team at hospital discharge, 7 days after anaesthesia, or death, whichever was first; at 1 month from a face-to-face consultation with an independent stroke physician or neurologist; and at 1 year from a telephone, postal questionnaire, or face-to-face consultation.

\section{Statistical analysis}

From randomisation, all patients were accounted for in the analysis, whether or not they had received the allocated treatment intervention, or even surgery at all. We made every effort to obtain all outcome data for every patient. We excluded patients from analyses if they had

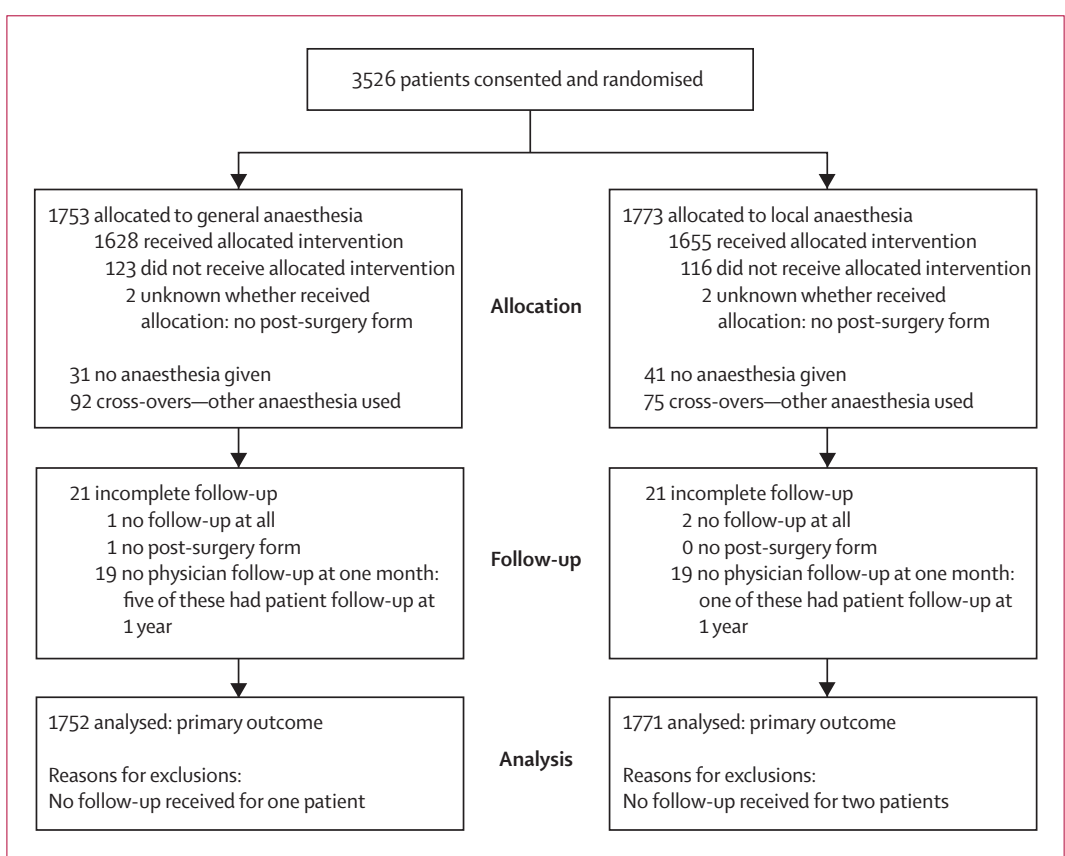

Figure 1: Trial profile 


\begin{tabular}{|c|c|c|}
\hline & $\begin{array}{l}\text { General } \\
\text { anaesthesia } \\
(\mathrm{N}=1753)\end{array}$ & $\begin{array}{l}\text { Local } \\
\text { anaesthesia } \\
(\mathrm{N}=1773)\end{array}$ \\
\hline Age (years) & $70(8 \cdot 8)$ & $69(8.8)$ \\
\hline Men & $1232(70 \%)$ & $1256(71 \%)$ \\
\hline Hypertension & $1334(76 \%)$ & $1382(78 \%)$ \\
\hline Systolic blood pressure $(\mathrm{mm} \mathrm{Hg})^{*}$ & $145(20.1)$ & $145(19 \cdot 7)$ \\
\hline Diastolic blood pressure $(\mathrm{mm} \mathrm{Hg})^{*}$ & $79(10 \cdot 3)$ & $79(10.8)$ \\
\hline Peripheral arterial disease & $425(24 \%)$ & $446(25 \%)$ \\
\hline Aortic aneurysm & $82(5 \%)$ & $70(4 \%)$ \\
\hline Coronary heart disease & $647(37 \%)$ & $627(35 \%)$ \\
\hline Cardiac failure & $90(5 \%)$ & $93(5 \%)$ \\
\hline Atrial fibrillation & $124(7 \%)$ & $111(6 \%)$ \\
\hline Diabetes & $435(25 \%)$ & $437(25 \%)$ \\
\hline Chronic lung disease ${ }^{\dagger}$ & $224(14 \%)$ & $219(14 \%)$ \\
\hline Current or ex-smoker & $1403(80 \%)$ & $1416(80 \%)$ \\
\hline \multicolumn{3}{|l|}{ Baseline surgical risk $1 \ddagger$} \\
\hline Low (score 0 ) & $878(50 \%)$ & $899(51 \%)$ \\
\hline Medium (score 1 ) & $729(42 \%)$ & $721(41 \%)$ \\
\hline High (score 2 or 3 ) & $146(8 \%)$ & $153(9 \%)$ \\
\hline \multicolumn{3}{|l|}{ Baseline surgical risk $2 \ddagger$} \\
\hline Very low (score 0-4) & $332(19 \%)$ & $331(19 \%)$ \\
\hline Low (score 5-9) & $695(40 \%)$ & $735(41 \%)$ \\
\hline Medium (score 10-14) & $482(27 \%)$ & $470(27 \%)$ \\
\hline High (score 15 or more) & $244(14 \%)$ & $237(13 \%)$ \\
\hline ASA grade I or IIS & $1147(65 \%)$ & $1159(65 \%)$ \\
\hline $\begin{array}{l}\text { Randomised artery to be operated } \\
\text { on (right) }\end{array}$ & $885(50 \%)$ & $863(49 \%)$ \\
\hline \multicolumn{3}{|l|}{ Indication for surgery } \\
\hline Asymptomatic carotid stenosis & $685(39 \%)$ & $677(38 \%)$ \\
\hline Carotid stroke only & $346(20 \%)$ & $346(20 \%)$ \\
\hline Cerebral TIA (carotid) only & $371(21 \%)$ & $375(21 \%)$ \\
\hline Retinal infarct only & $32(2 \%)$ & $36(2 \%)$ \\
\hline Amaurosis fugax only & $155(9 \%)$ & $173(10 \%)$ \\
\hline \multirow[t]{2}{*}{$\begin{array}{l}\text { More than one of the above } \\
\text { events }\end{array}$} & $164(9 \%)$ & $166(9 \%)$ \\
\hline & \multicolumn{2}{|c|}{ (Continues in next column } \\
\hline
\end{tabular}

missing data relevant to a particular analysis, as indicated in the results. We calculated the unadjusted relative and absolute differences in the proportion of patients with a primary outcome overall, and in three prespecified subgroups: contralateral versus non-contralateral carotid occlusion, because predicting and avoiding a perioperative low-flow ischaemic stroke by appropriate shunting in the former group can be particularly important; more or less than 75 years old-a cut-off defined early in the trial using the age distribution of patients alone, and not by referring to the outcome data; and low versus high baseline risk of surgical stroke or death with a previously published but non-validated model. ${ }^{8}$ Post-hoc subgroups were baseline risk of surgical stroke or death using a new model (Bond R, unpublished), trainee versus experienced surgeons and anaesthetists, symptomatic versus asymptomatic stenosis, and country (UK versus others). We analysed these subgroups with logistic regression,

\begin{tabular}{|c|c|c|}
\hline & $\begin{array}{l}\text { General } \\
\text { anaesthesia } \\
(\mathrm{N}=1753)\end{array}$ & $\begin{array}{l}\text { Local } \\
\text { anaesthesia } \\
(\mathrm{N}=1773)\end{array}$ \\
\hline \multicolumn{3}{|l|}{ (Continued from previous column) } \\
\hline $\begin{array}{l}\text { Stenosis of randomised artery to } \\
\text { be operated on (\%) }\end{array}$ & $81(11 \cdot 1)$ & $81(11 \cdot 3)$ \\
\hline Contralateral carotid occlusion & $150(9 \%)$ & $160(9 \%)$ \\
\hline \multicolumn{3}{|l|}{ Stenosis assessed byll } \\
\hline Ultrasound & $1671(95 \%)$ & $1666(94 \%)$ \\
\hline MR angiography & $277(16 \%)$ & $300(17 \%)$ \\
\hline CT angiography & $224(13 \%)$ & $227(13 \%)$ \\
\hline Catheter angiography & $220(13 \%)$ & $226(13 \%)$ \\
\hline $\begin{array}{l}\text { Infarct on side of brain relevant to } \\
\text { operation }\end{array}$ & $363(35 \%)$ & $409(38 \%)$ \\
\hline UK patient & $806(46 \%)$ & $820(46 \%)$ \\
\hline \multicolumn{3}{|c|}{ Antithrombotic drugs used pre-randomisation ${ }^{* *}$} \\
\hline Aspirin & $889(65 \%)$ & $913(67 \%)$ \\
\hline Clopidogrel & $105(8 \%)$ & $117(9 \%)$ \\
\hline Dipyridamole & $86(6 \%)$ & $94(7 \%)$ \\
\hline Warfarin & $21(2 \%)$ & $17(1 \%)$ \\
\hline
\end{tabular}

Data are number (\%) or mean (SD), unless otherwise stated. $A S A=A m e r i c a n$ Society of Anesthesiologists. TIA=transitory ischaemic attack. No scan to image any infarct was done in 706 patients under general anaesthesia and 705 under local anaesthesia. *Systolic and diastolic blood pressures were unknown for four patients undergoing surgery with general anaesthesia and six with local anaesthesia. TChronic lung disease was not assessed in the first 158 patients under general anaesthesia and 169 under local anaesthesia. ¥Baseline surgical risk 1 of stroke or death: patients score one point each for having systolic blood pressure higher than $180 \mathrm{~mm} \mathrm{Hg}$, being female, and having peripheral arterial disease. Missing blood pressure values were assumed to be $180 \mathrm{~mm} \mathrm{Hg}$ or less. Scores of 2 or 3 were combined into one group because of small numbers. ${ }^{8}$ Baseline surgical risk 2 of stroke or death, patients score: age 75 years old or older $=2$ points, hypertension $=3$ points, female $=4$ points, diabetes $=5$ points, symptomatic cerebral event $=6$ points, contralateral occlusion $=9$ points, redo surgery $=10$ points, emergency surgery $=29$ points (Bond $R_{r}$ unpublished). SASA grade I=healthy patient; grade II=mild systemic disease with no functional limitation; grade III=severe systemic disease with definite functional limitation; grade IV=severe systemic disease that is a constant threat to life; grade $\mathrm{V}=$ moribund patient who is not expected to survive for $24 \mathrm{~h}$ with or without surgery. ISymptomatic stenosis is defined as a patient who has had symptoms on the relevant side at any time in the past. ||Patients could be assessed with more than one type of imaging. ${ }^{* *}$ This information was recorded after randomisation in 1358 patients under general anaesthesia and 1371 under local anaesthesia. It was not recorded in the first part of the trial.

Table 1: Patient demographic and baseline characteristics

with $\mathrm{p}$ values calculated from the change in log likelihood on entering the interaction between the subgroup effect and treatment effect into the model. We did the analyses in SAS version 9.1.3, Revman 5.0, and CIA version 2.1.0.

\section{Role of the funding source}

The funding source had no role in the study design, data collection, data analysis, data interpretation, or writing of the report. One senior member of the European Society for Vascular Surgery was part of the steering committee throughout the trial. All authors participated in the design and conduct of the GALA trial, and in writing and editing the manuscript. They have all seen the final version. The corresponding author had full access to all the data in the study and had final 


\begin{tabular}{|c|c|c|}
\hline & $\begin{array}{l}\text { General } \\
\text { anaesthesia }\end{array}$ & $\begin{array}{l}\text { Local } \\
\text { anaesthesia }\end{array}$ \\
\hline \multicolumn{3}{|l|}{ No anaesthesia given } \\
\hline Death before operation & 1 & 1 \\
\hline Stroke before operation & 1 & 1 \\
\hline Carotid artery occluded before operation & 8 & 8 \\
\hline $\begin{array}{l}\text { Too ill (condition unrelated to carotid } \\
\text { disease) }\end{array}$ & 7 & 6 \\
\hline $\begin{array}{l}\text { Carotid stenosis or clinical symptoms too } \\
\text { mild to warrant surgery }\end{array}$ & 4 & 11 \\
\hline Patient refusal & 9 & 13 \\
\hline Carotid-stent procedure done instead & 1 & 1 \\
\hline Total & 31 & 41 \\
\hline \multicolumn{3}{|c|}{ Anaesthesia used from the outset was opposite to that allocated } \\
\hline Medical decision & 41 & 20 \\
\hline Administrative issues & 15 & 9 \\
\hline Patient's decision & 29 & 44 \\
\hline Reason unknown & 7 & 2 \\
\hline Total & 92 & 75 \\
\hline \multicolumn{3}{|l|}{ Conversions after initiation of anaesthesia } \\
\hline \multicolumn{3}{|c|}{ After administration of anaesthesia and before surgery } \\
\hline Patient's decision & .. & 6 \\
\hline Problems with positioning patient on table &.. & 3 \\
\hline $\begin{array}{l}\text { Patient's condition deteriorated after } \\
\text { local-anaesthetic block }\end{array}$ & .. & 8 \\
\hline \multicolumn{3}{|l|}{ After start of surgery } \\
\hline Pain at operative site & .. & 9 \\
\hline $\begin{array}{l}\text { General discomfort, anxiety, } \\
\text { claustrophobia, and restlessness }\end{array}$ & .. & 25 \\
\hline Physiological instability & .. & 5 \\
\hline Protracted or difficult surgery & .. & 6 \\
\hline $\begin{array}{l}\text { Neurological deterioration on } \\
\text { cross-clamping* }\end{array}$ & .. & 7 \\
\hline Total & 0 & 69 \\
\hline \multicolumn{3}{|c|}{$\begin{array}{l}\text { It was known that one patient who was randomly assigned to general anaesthesia } \\
\text { was anaesthetised, but not which anaesthetic the patient actually received. We } \\
\text { have assumed that this patient received general anaesthesia, as randomised. The } \\
\text { information about reasons for non-compliance was generated from free text } \\
\text { rather than predetermined categories and, in many cases, it was multifactorial. } \\
\text { We categorised it according to the predominant problem listed. "We do not have } \\
\text { exact reasons recorded for this, but six patients received a shunt and the seventh } \\
\text { had a high bifurcation. }\end{array}$} \\
\hline
\end{tabular}

responsibility for the decision to submit for publication.

\section{Results}

Recruitment ran from June, 1999 to October, 2007. Database was locked on May 1, 2008. We used the first randomisation for ten patients who were inadvertently randomised twice. We removed one patient from the database because consent for the trial was not obtained, leaving 3526 for analysis (figure 1). Table 1 shows the baseline patient characteristics. We received post-surgery forms from all but two patients in each treatment group (99.9\%).

\begin{tabular}{|c|c|c|}
\hline & $\begin{array}{l}\text { General } \\
\text { anaesthesia }\end{array}$ & $\begin{array}{l}\text { Local } \\
\text { anaesthesia }\end{array}$ \\
\hline $\begin{array}{l}\text { Post-surgery form received and anaesthesia } \\
\text { administered }\end{array}$ & 1720 & 1730 \\
\hline Trainee surgeon* & $242(14 \%)$ & $210(12 \%)$ \\
\hline Trainee anaesthetist $\dagger$ & $246(16 \%)$ & $213(14 \%)$ \\
\hline Duration of surgery $(\mathrm{min}) \neq$ & $93(33 \cdot 6)$ & $93(36 \cdot 0)$ \\
\hline Premedication useds & $905(53 \%)$ & $877(51 \%)$ \\
\hline \multicolumn{3}{|l|}{ Type of surgery 9} \\
\hline Conventional & $1237(78 \%)$ & $1145(72 \%)$ \\
\hline Eversion & $317(20 \%)$ & $409(26 \%)$ \\
\hline Exploration only & $3(0 \cdot 2 \%)$ & $4(0 \cdot 3 \%)$ \\
\hline Other & $22(1 \%)$ & $14(1 \%)$ \\
\hline Procedure abandoned & $4(0.2 \%)$ & $9(1 \%)$ \\
\hline Shunt used & $738(43 \%)$ & $248(14 \%)$ \\
\hline \multicolumn{3}{|l|}{ Reasons for using shunt } \\
\hline $\begin{array}{l}\text { Neurological deterioration (only } \\
\text { applicable in patients receiving local } \\
\text { anaesthesia) }\end{array}$ & $6 \|$ & 150 \\
\hline Used routinely & 369 & $35 \|$ \\
\hline Drop in velocity on TCD & 45 & $3 \|$ \\
\hline Unable to use TCD & 58 & $5 \|$ \\
\hline $\begin{array}{l}\text { Contralateral carotid occlusion or near } \\
\text { occlusion }\end{array}$ & 38 & $5 \|$ \\
\hline Low stump pressure & 108 & $15 \|$ \\
\hline $\begin{array}{l}\text { Contralateral carotid stenosis (but not } \\
\text { occluded or nearly occluded) }\end{array}$ & 4 & $7 \|$ \\
\hline Recent stroke & 5 & $3 \|$ \\
\hline $\begin{array}{l}\text { Unusual or damaged veins or arteries } \\
\text { in head or neck }\end{array}$ & 2 & $2 \|$ \\
\hline EEG or evoked potentials changed & 8 & $1 \|$ \\
\hline Blood pressure dropped & 4 & $1 \|$ \\
\hline Falling brain oxygen levels & 1 & 0 \\
\hline Operation converted to vein bypass & 1 & 0 \\
\hline Unknown & 89 & 21 \\
\hline \multicolumn{3}{|l|}{ Blood pressure manipulation** } \\
\hline Manipulated up & $667(43 \%)$ & $267(17 \%)$ \\
\hline Manipulated down & $208(13 \%)$ & $433(28 \%)$ \\
\hline Manipulated up and down & $259(17 \%)$ & $153(10 \%)$ \\
\hline Not manipulated & $435(28 \%)$ & $717(46 \%)$ \\
\hline Patch used & $861(50 \%)$ & $728(42 \%)$ \\
\hline Intraoperative heparin used ${ }^{* *}$ & $1682(98 \%)$ & $1678(97 \%)$ \\
\hline
\end{tabular}

Data are number (\%) or mean (SD). EEG=Electroencephalograph. TCD=Trans-cranial doppler. *Experience of surgeon unknown for two patients receiving general anaesthesia and five receiving local anaesthesia. †Experience of anaesthetist not recorded in first 149 patients receiving general anaesthesia and 161 receiving local anaesthesia. $\ddagger$ Duration of surgery available for 1711 receiving general anaesthesia and 1717 receiving local anaesthesia. SUse of premedication unknown for two patients receiving general anaesthesia and three receiving local anaesthesia. ๆType of surgery not recorded in first 137 receiving general anaesthesia and 149 receiving local anaesthesia. ||Most patients who had these reasons for using shunts received the opposite type of anaesthetic. All six patients allocated to general anaethesia who received a shunt because of neurological deterioration received the opposite type of anaesthetic (local anaesthetic). 50 of 77 (65\%) patients receiving local anaesthetic with reasons for using shunts other than neurological deterioration received the opposite type of anaesthetic (26 patients) or converted (24 patients). **Blood-pressure manipulation not recorded in first 151 receiving general anaesthesia and 160 receiving local anaesthesia. $\dagger$ Intra-operative heparin use unknown for one patient receiving general anaesthesia.

Table 3: Surgical and anaesthetic procedure 


\begin{tabular}{|c|c|c|}
\hline & $\begin{array}{l}\text { General } \\
\text { anaesthesia }\end{array}$ & $\begin{array}{l}\text { Local } \\
\text { anaesthesia }\end{array}$ \\
\hline $\begin{array}{l}\text { Post-surgery or physician follow-up } \\
\text { complete }\end{array}$ & 1752 & 1771 \\
\hline Stroke* & $70(4 \cdot 0 \%)$ & $66(3 \cdot 7 \%)$ \\
\hline Fatal & 15 & 11 \\
\hline Non-fatal & 55 & 55 \\
\hline \multicolumn{3}{|l|}{ Modified Rankin 6 months after stroke } \\
\hline $0-2$ & 41 & 40 \\
\hline $3-5$ & 14 & 14 \\
\hline Dead & 15 & 12 \\
\hline Ipsilateral to surgery & 54 & 57 \\
\hline Contralateral to surgery & 15 & 7 \\
\hline Vertebrobasilar & 1 & 2 \\
\hline Cerebral infarction & 37 & 41 \\
\hline Retinal infarction & 2 & 3 \\
\hline Cerebral haemorrhage & 11 & 7 \\
\hline Unknown pathology & 20 & 15 \\
\hline $\begin{array}{l}\text { Events prevented per } 1000 \text { patients } \\
\text { with local anaesthesia }(95 \% \mathrm{Cl})\end{array}$ & .. & $\begin{array}{c}3 \\
(-10 \text { to } 16)\end{array}$ \\
\hline Myocardial infarction & $4(0 \cdot 2 \%)$ & $9(0.5 \%)$ \\
\hline Fatal & 1 & 3 \\
\hline Non-fatal & 3 & 6 \\
\hline $\begin{array}{l}\text { Events prevented per } 1000 \text { patients } \\
\text { with local anaesthesia }(95 \% \mathrm{Cl})\end{array}$ & .. & $\begin{array}{l}-3 \\
(-8 \text { to } 2)\end{array}$ \\
\hline Other vascular death & 9 & 5 \\
\hline Stroke (onset before randomisation) & 1 & 0 \\
\hline Coronary heart disease, sudden & 2 & 0 \\
\hline $\begin{array}{l}\text { Sudden death without further } \\
\text { information }\end{array}$ & 1 & 1 \\
\hline Other coronary heart disease & 2 & 3 \\
\hline Other cardiac (non-coronary) & 2 & 0 \\
\hline Aortic aneurysm rupture & 1 & 0 \\
\hline Pulmonary embolism & 0 & 0 \\
\hline \multirow[t]{2}{*}{ Other } & 0 & 1 \\
\hline & \multicolumn{2}{|c|}{ (Continues in next column) } \\
\hline
\end{tabular}

Slightly more patients who were allocated to local anaesthesia did not have surgery, because at examination after randomisation it was decided the stenosis or symptoms were too mild (table 2). 92 of $1751(5 \cdot 3 \%$ ) patients assigned to general anaesthesia and 75 of $1771(4 \cdot 2 \%)$ assigned to local anaesthesia underwent surgery but received the opposite type of anaesthetic to that allocated at randomisation. Patients who were allocated to general anaesthesia were more likely than those allocated to local anaesthesia to receive the opposite type of anaesthetic because of a medical decision, whereas patients allocated to local anaesthesia were more likely than those allocated to general anaesthesia to receive the opposite type of anaesthetic because of patient's decision. 69 of $1771(3.9 \%)$ patients assigned to local anaesthesia received general anaesthesia after initiation of anaesthesia, 17 before and 52 after the start of surgery.

For patients who received anaesthesia, median time from randomisation to surgery was 1 day in both

\begin{tabular}{|c|c|c|}
\hline & $\begin{array}{l}\text { General } \\
\text { anaesthesia }\end{array}$ & $\begin{array}{l}\text { Local } \\
\text { anaesthesia }\end{array}$ \\
\hline \multicolumn{3}{|l|}{ (Continued from previous column) } \\
\hline Non-vascular death & 0 & 0 \\
\hline Unknown cause of death & 1 & 0 \\
\hline Death (any cause) & $26(1 \cdot 5 \%)$ & $19(1 \cdot 1 \%)$ \\
\hline $\begin{array}{l}\text { Events prevented per } 1000 \text { patients } \\
\text { with local anaesthesia }(95 \% \mathrm{Cl})\end{array}$ & .. & $\begin{array}{c}4 \\
(-3 \text { to } 12)\end{array}$ \\
\hline $\begin{array}{l}\text { Stroke (including retinal infarction) or } \\
\text { death }\end{array}$ & $81(4 \cdot 6 \%)$ & $74(4.2 \%)$ \\
\hline $\begin{array}{l}\text { Events prevented per } 1000 \text { patients } \\
\text { with local anaesthesia }(95 \% \mathrm{Cl})\end{array}$ &. & $\begin{array}{c}4 \\
(-9 \text { to } 18)\end{array}$ \\
\hline $\begin{array}{l}\text { Stroke (including retinal infarction), } \\
\text { myocardial infarction, or death }\end{array}$ & $84(4 \cdot 8 \%)$ & $80(4 \cdot 5 \%)$ \\
\hline $\begin{array}{l}\text { Events prevented per } 1000 \text { patients } \\
\text { with local anaesthesia }(95 \% \mathrm{Cl})\end{array}$ &.. & $\begin{array}{c}3 \\
\text { (-11 to } 17)\end{array}$ \\
\hline
\end{tabular}

Data are number $(\%)$ or number $(95 \% \mathrm{Cl})$. Only one event per patient has been counted. If a patient had multiple events, the event included in this table is the fatal one (if there was one), and the first non-fatal one for all other patients. Stroke events are counted in preference to coronary events, and severe events are counted over non-severe events. *The number of fatal strokes is different from the number of deaths 6 months after the stroke outcome event, because one patient died exactly 6 months after the stroke outcome event of an unknown cause. There were two events in patients receiving general anaesthesia and two in patients receiving local anaesthesia (one stroke and one death in each group) after randomisation but before surgery could be done (surgery was cancelled in all cases).

Table 4: Primary outcomes between randomisation and 30 days after anaesthesia (or after randomisation for patients who were not anaesthetised)

treatment groups (IQR 1 to 2 days for local anaesthesia and 1 to 3 days for general anaesthesia). The median time between the last relevant neurological event and surgery, for symptomatic patients, was 70 days (IQR 27 to 138) in the general anaesthesia group, and 72 days (IQR 28 to 162) in the local anaesthesia group.

Primary outcome data were available from 1752 of 1753 patients allocated to general anaesthesia, and 1771 of 1773 patient allocated to local anaesthesia. Almost all patients were followed up by an independent neurologist or stroke physician, with only a few assessed just by= the surgical or anaesthetic team (equally balanced between the treatment groups).

Slightly more patients assigned to local anaesthesia than those assigned to general anaesthesia had a conventional rather than an eversion endarterectomy (table 3). Endarterectomy was repaired with a patch more frequently in the general anaesthesia than in the local anaesthesia group $(50 \%$ versus $42 \%, \mathrm{p}<0 \cdot 001)$. The mean operating (skin-to-skin) time was similar in both groups (table 3). The proportion of operations done by trainee surgeons and anaesthetists was similar in the two groups, as was the use of heparin. Premedication was used in about $50 \%$ of patients in both groups.

Most patients undergoing general anaesthesia received gaseous anaesthetic agents (volatile agents 1244 [84\%], nitrous oxide 616 [41\%]) and muscle relaxants (1481 [91\%]), and a smaller number received total intravenous 


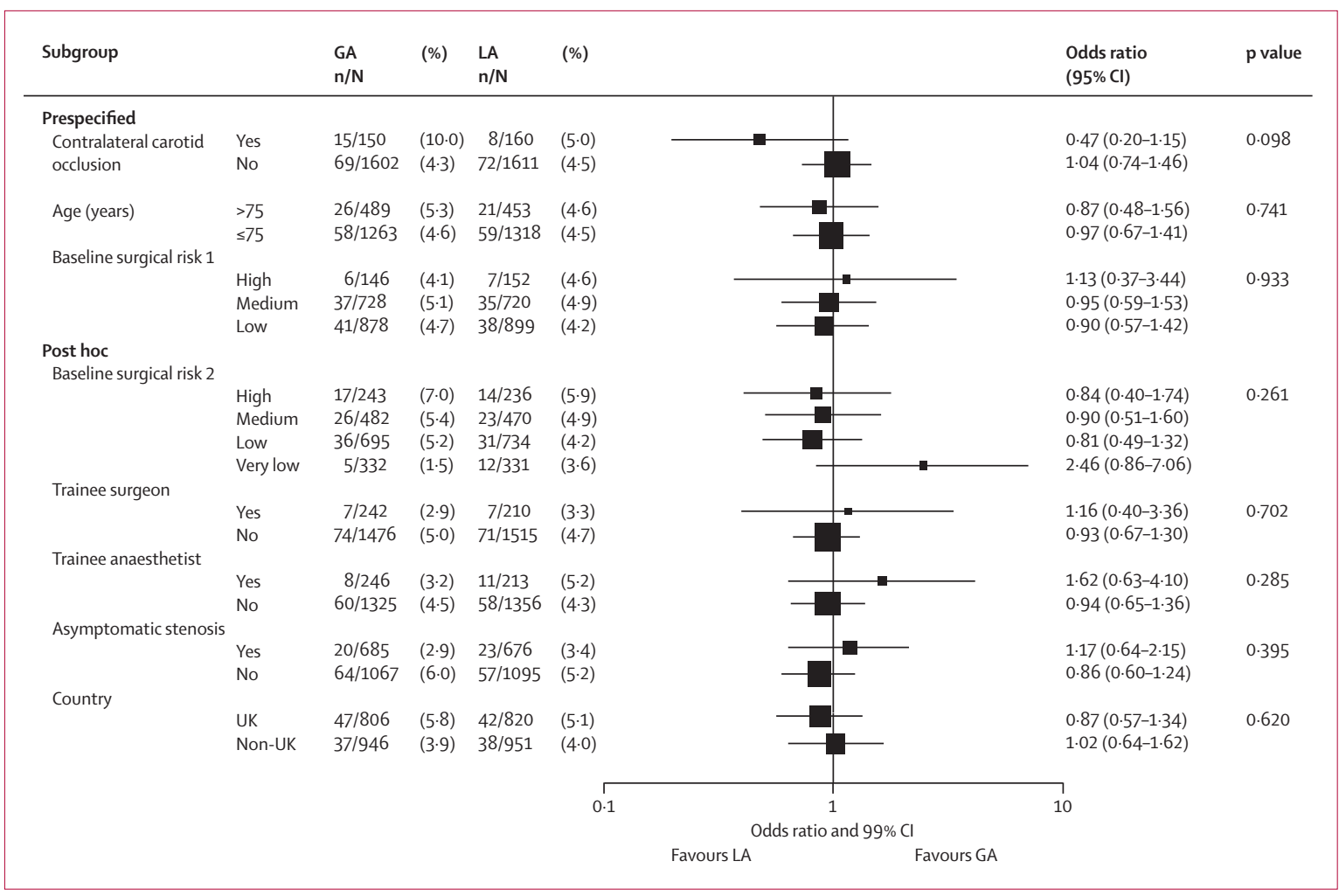

Figure 2: Subgroup analyses on primary outcome of stroke (including retinal infarction), myocardial infarction, or death between randomisation and 30 days after anaesthesia (or after randomisation for those patients who did not receive any anaesthetic)

$\mathrm{GA}=$ general anaesthesia. $\mathrm{LA}=$ local anaesthesia. Big squares represent studies with small $95 \% \mathrm{Cl}$ (ie, with more information); the horizontal lines represent the $95 \% \mathrm{Cls}$.

anaesthesia (442 [30\%]). Most patients undergoing local anaesthesia received a cervical-plexus block (1532 [93\%]), together with local infiltration by the anaesthetist (1281 [77\%]) and supplementary infiltration by the surgeon (1050 [64\%]). 791 (48\%) had some intra-operative sedation and 732 (44\%) intra-operative analgesia. More patients allocated to general anaesthesia than those allocated to local anaesthesia $(\mathrm{p}<0.001)$ had their blood pressure manipulated up, and more patients allocated to local anaesthesia than those allocated to general anaesthesia $(\mathrm{p}<0 \cdot 001)$ had their blood pressure manipulated down or not manipulated at all.

Primary outcomes arose in 84 of 1752 (4.8\%) patients allocated to general anaesthesia and 80 of $1771(4.5 \%)$ patients allocated to local anaesthesia. Three events every 1000 treated were prevented under local anaesthesia (risk ratio [RR] $0 \cdot 94$ [95\% CI $0 \cdot 70$ to $1 \cdot 27$ ]; table 4). If the patients with missing general anaesthesia data were assumed to have had good outcomes, and the patients with missing local anaesthesia data poor outcomes, then local anaesthesia might prevent two events every 1000 treated ( $95 \%$ CI -12 to 16$)$. If the four patients who had an event before anaesthesia, together with those who never had surgery, underwent exploration only, or when surgery was abandoned, and the cross-overs and conversions were all removed, then there were 79 primary outcomes in $1621(4.9 \%)$ patients under general anaesthesia and 64 in 1575 (4.1\%) patients under local anaesthesia. Eight events every 1000 treated were prevented with local anaesthesia ( $95 \%$ CI -6 to +23$)$, similar to what we found with the intention-to-treat analysis.

Death occurred between randomisation and 30 days after anaesthesia (or after randomisation for those who never had surgery) in slightly more patients under general than under local anaesthesia (table 4). Four events every 1000 treated were prevented (RR $0 \cdot 72$ [95\% CI $0 \cdot 40$ to $1 \cdot 30]$ ). Three events every 1000 treated were prevented by local anaesthesia $(0.93[0.67$ to 1.30$])$. Slightly more myocardial infarctions happened in patients under local anaesthesia than under general anaesthesia. None of these differences was statistically significant.

In four patients allocated to general anaesthesia and nine to local anaesthesia (one of whom actually received general anaesthesia), anaesthesia was initiated but no endarterectomy was done. The patient who was randomised to local anaesthesia but received general anaesthesia had heart failure under anaesthesia before surgery. Reasons for stopping the procedure in the other patients under general anaesthesia were failure to intubate, severe bronchospasm after intubation, hypoxia with hypertension, and atrial fibrillation. The reasons for stopping the procedure in the patients under local 


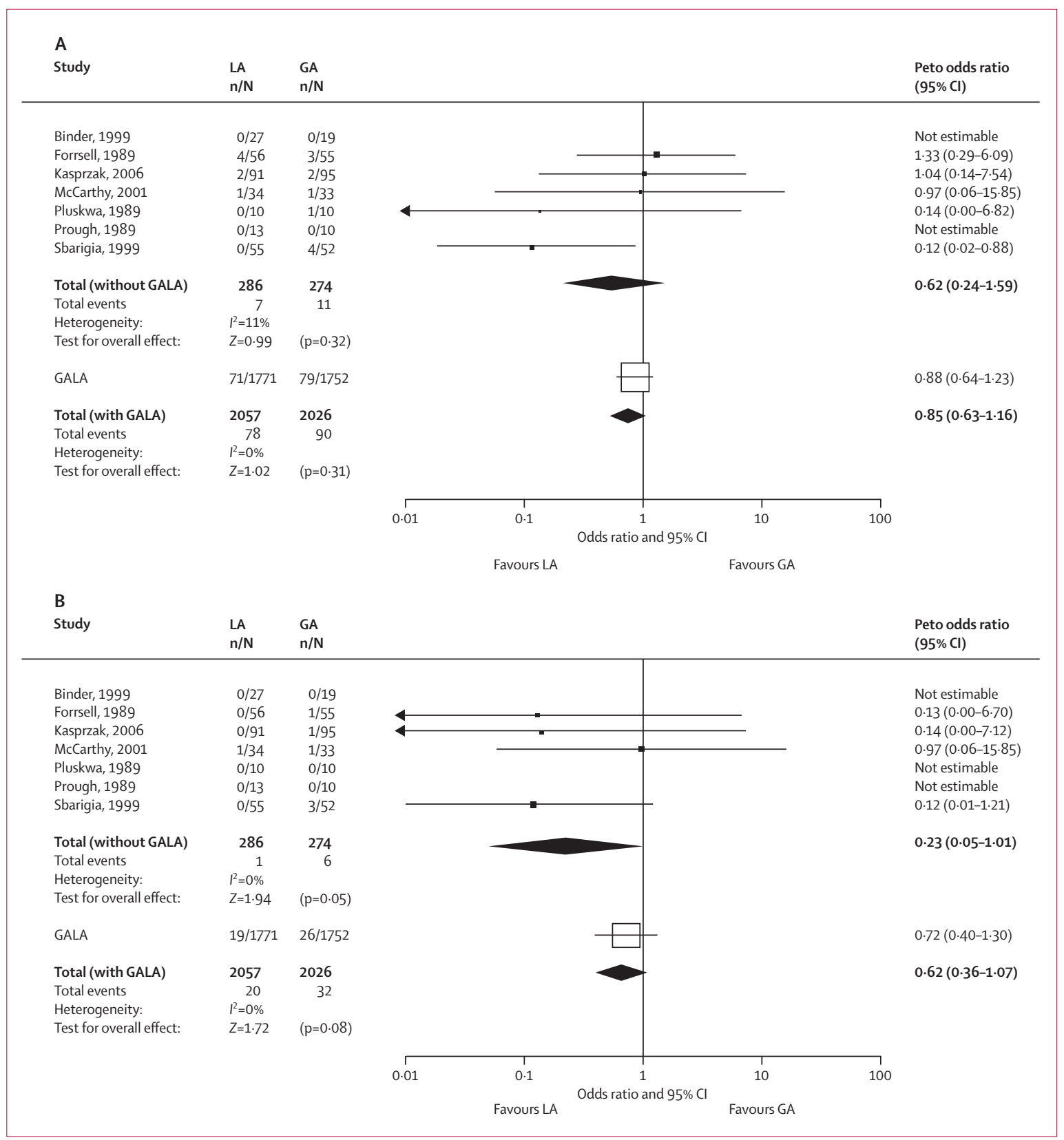

Figure 3: Cochrane review for outcome of stroke or death (A) or for outcome of death (B)

The plot shows the Peto odds ratio (squares) and $95 \% \mathrm{Cl}$ (horizontal lines) for each study. Bigger squares represent studies with smaller $95 \% \mathrm{Cl}$. The width of the diamonds represents the $\mathrm{Cl}$ for each meta-analysis (the totals) of studies. The GALA results in this plot do not include retinal infarcts, because these were not included in the Cochrane review. GA=general anaesthesia. $\mathrm{LA}=$ local anaesthesia.

anaesthesia were chest pain after regional block, bradycardia after skin incision, severe hypertension, vagal reaction followed by severe hypertension, epileptic seizures, loss of consciousness (possibly caused by injecting anaesthetic into the vertebral artery), respiratory insufficiency due to presumed phrenic-nerve blockade, and signs of cerebral ischaemia during awake testing.

$184(10 \cdot 5 \%)$ patients under general anaesthesia and $213(12 \cdot 0 \%)$ under local anaesthesia had cranial-nerve injuries. $146(8.3 \%)$ patients under general anaesthesia and $150(8.5 \%)$ under local anaesthesia had wound haematoma needing re-operation in $45(2.6 \%)$ and $40(2 \cdot 3 \%)$ patients, respectively. $35(2 \cdot 0 \%)$ patients under general anaesthesia and $33(1.9 \%)$ under local anaesthesia had postoperative chest infections. None of these differences was statistically significant.

Time to first stroke, myocardial infarction, or death at 1 year did not differ significantly between the two groups, 
although local anaesthesia gave slightly better results (Log-rank test $p=0 \cdot 094$ ). We showed no significant differences in any of the timing-related outcomes that we measured (although the time in the operating theatre was not recorded, the operating time was similar; table 3), and no substantial difference for quality of life at about 30 days in patients who lived long enough to complete the forms.

The effect of general and local anaesthesia on the primary outcome was not significantly different in the three prespecified subgroups (figure 2). However, local anaesthesia seemed to be more effective than general anaesthesia for patients with contralateral carotid occlusion (figure 2). In these patients, 12 strokes and one retinal infarct occurred in 150 patients under general anaesthesia versus six strokes and one retinal infarct in 160 patients under local anaesthesia. These strokes were contralateral to the operated artery in $7(4.7 \%)$ patients under general anaesthesia and $2(1 \cdot 2 \%)$ under local anaesthesia. However, these findings should be viewed with caution.

The original model for baseline surgical risk did not fit our data well, because the proportion of primary outcomes did not increase with increasing risk score. Consequently, we did a post-hoc analysis with a recently developed, but as yet unpublished, measure of baseline surgical risk that did not use GALA data in its derivation (Bond $\mathrm{R}$, unpublished). This new analysis predicted the overall outcome better than did the original analysis, but it was still not clear whether local or general anaesthesia was better in patients at different risks. No evidence existed of an interaction between type of anaesthesia and either country (UK versus non-UK, $p=0 \cdot 62$ ), or symptomatic versus asymptomatic stenosis $(p=0 \cdot 40)$. The higher surgical risk in the UK than in other countries might have been the result of surgeons in non-UK centres being much more likely to operate on asymptomatic than symptomatic carotid stenosis ( $58 \%$ vs $16 \%$ ).

There was a suggestion that trainee surgeons and anaesthetists had better results with general anaesthesia than with local anaesthesia, but this was not statistically significant $(p=0.7$ for surgeons and $p=0.3$ for anaesthetists).

\section{Discussion}

The hypothesis that local anaesthesia is better than general anaesthesia for carotid endarterectomy is based on the idea that it is associated with more appropriate and less frequent shunt use, fewer cardiorespiratory complications, and preserved cerebrovascular autoregulation. ${ }^{10}$

However, in this study, although general anaesthesia was associated with a slightly higher risk than local anaesthesia of perioperative stroke, myocardial infarction, or death, this difference was not statistically significant. Patients with contralateral-carotid occlusion might be an exception; their risk of stroke seemed higher during surgery under general anaesthesia than under local anaesthesia, although this was not statistically significant.

Nonetheless, local anaesthesia was associated with an absolute excess of up to $1 \%$ more events, or up to $2 \%$ fewer events, than general anaesthesia. However, even when our results are added to those of the randomised trials in the Cochrane review, there is still no clear answer (figure 3), with GALA dominating the analysis by providing $86 \%$ of the patients. Also, we could not show any difference in quality of life neither at about 1 month after surgery nor in duration of surgery, time spent in intensive therapy or high-dependency units, or overall length of hospital stay.

The power of the study was reduced by the lower than anticipated perioperative risk of stroke, perhaps because surgeons and anaesthetists had chosen to avoid randomisation of high-risk patients who they deemed unsuitable for one or the other type of anaesthetic, and also perhaps because of the improvement of surgical and anaesthetic techniques over the years. However, even if we had reached our planned sample size of 5000 and the absolute risk of primary outcome had been the same, the difference between general anaesthesia and local anaesthesia would still not have been significant.

The absence of blinding might have caused bias in the recognition or assessment of outcomes. However, in most patients $(99 \%)$ an independent stroke physician or neurologist assessed the primary outcome, and all case summaries and their audit were done completely blind to treatment allocation.

Some might think that the interventions-randomised and not-should have been more strictly standardised; however, this would have been impractical in a long-term multicentre international study because, if centres had been forced into practices they were not familiar with or did not approve of, strict standardisation would have compromised recruitment.

Lengths of stay in groups under general anaesthesia or local anaesthesia did not differ maybe because management protocols were not adjusted to take advantage of the potential opportunities that surgery under local anaesthesia might have offered. Quality-of-life data may have been measured too late after surgery to capture any early advantage of local anaesthesia.

Anaesthetists and surgeons have suggested that local anaesthesia rather than general anaesthesia should reduce perioperative morbidity and mortality, particularly for patients with severe comorbidities. However, data to support this hypothesis are scarce. Most clinical trials in various major surgical procedures have failed to show a convincing benefit for local anaesthesia. . $^{6,11,12}$

For carotid surgery, one possible benefit of local anaesthesia could be the increase in systemic blood pressure that occurs after carotid clamping under local anaesthesia ${ }^{10}$ and its effect in maintaining cerebral perfusion. Local anaesthesia could also reduce the stress 
response to surgery, although other factors (physical scale of surgery, size of incision, internal visceral damage, and blood loss) affect this response more than the type of anaesthesia. ${ }^{13}$ Although patients needing carotid surgery typically have severe comorbidity, surgery needs a small incision compared with many other vascular operations, and is associated with minimal blood loss and ischaemia re-perfusion. Thus, the stress response is likely to be small and the frequency of complications, such as myocardial infarction, chest infection, and venous thromboembolism, can also be expected to be small compared, for example, with open abdominal aortic aneurysm repair, as we showed in the GALA study.

An unknown proportion of perioperative strokes are the result of technical issues at the endarterectomy site (which at first sight may not seem to be affected by the type of anaesthesia) rather than of low cerebral-blood flow during carotid clamping. However, more hurried surgery during local anaesthesia or increased use of shunts under general anaesthesia might result in arterial trauma, and subsequent thrombosis and embolism. Although in the GALA study duration of surgery did not differ between the two groups, fewer arteries were patched under local anaesthesia, which might have increased the risk of neurological complications in this group. ${ }^{14}$

Local anaesthesia has other possible disadvantages ${ }^{15,16}$ that might offset some of its potential benefits during carotid surgery. Pain and anxiety during the procedure might increase the risk of myocardial ischaemia, although patients in this study frequently received premedication, and supplementary intra-operative sedation and analgesia to keep this to a minimum. A patient should be alert enough to do awake neurological testing during carotid clamping, but short periods of deep sedation might be needed if the patient becomes restless or uncomfortable, particularly towards the end of the procedure. Such problems are more likely if patients are anxious, agitated, or claustrophobic, or have comorbidities that make it difficult to lie in one position for any length of time (such as cardiopulmonary disease or joint problems).

Nonetheless, conversion to general anaesthesia may still be needed (1.4\% of patients in the GALA study), which is not without risk, particularly if done in a hurried, uncontrolled way. Access to the airway is compromised by the surgical drapes, and anaesthetic-induced hypotension might cause cerebral hypoperfusion. Also, not all patients are psychologically able to tolerate procedures while awake.

Occasionally, administration of local anaesthesia for carotid surgery results in needle damage to vulnerable structures (vertebral artery during deep cervical-plexus block, intravascular injection, and phrenic-nerve block) and might cause haematoma. ${ }^{15,16}$ In this study, $4.4 \%$ of patients under local anaesthesia had complications that led to cancellation of surgery or conversion to general anaesthesia.
In regard to major perioperative complications of stroke, myocardial infarction, and death, there is no reason to prefer general over local anaesthesia, or vice versa, as routine for carotid endarterectomy. Similarly, we showed no definite evidence that the type of anaesthesia affects length of hospital stay or quality of life. Ideally, therefore, surgical and anaesthetic teams should be competent in both techniques because a patient might prefer, or there might be a medical reason to choose one rather than the other.

\section{Conflict of interest statement}

We declare that we have no conflict of interest.

\section{Acknowledgements}

We thank the Health Foundation and the European Society for Vascular Surgery for funding the study; all the participants who consented to be randomised; and the trial staff and collaborators for their hard work. APB was partly funded by the Oxford Biomedical Research Centre.

\section{GALA Trial Coordination}

Writing Committee: S C Lewis, C P Warlow, A R Bodenham, B Colam, P M Rothwell, D Torgerson, D Dellagrammaticas, M Horrocks, C Liapis, A P Banning, M Gough, M J Gough, for the GALA Collaborative group. GALA Trial Coordinating Centre: The University of Edinburgh,

UK-B Colam, A Fraser, S Grant, J Hunter, A Leigh-Brown, S C Lewis, M Paterson, V Soosay, A Young, C P Warlow, A Williamson. Additional GALA Trial Support: Ninewells Hospital, Dundee, UK (Z Dean); Ospedale “Beato Giacomo Villa” di Citta' della Pieve, Perugia, Italy (T Mazzoli, S Ricci); King's College Hospital, London, UK (D Valenti).

Independent Data Monitoring Committee: J Bamford, J Beard, M Dearden, G Murray, V Ruckley (the trial statistician SCL attended as a non-voting member).

National Coordinators: P E Norman (Australia), P Sedivy (Czech Republic), A Idla (Estonia), T Schmitz-Rixen (Germany), G Maritati (Italy).

Steering Committee: A P Banning, A Bodenham, B Colam,

D Dellagrammaticas, M Gough, M J Gough, M Horrocks, S C Lewis, C Liapis, P M Rothwell, D Torgerson, C P Warlow.

GALA Trial Collaboration by country (number of patients randomised): LKH-Graz West, Austria (25)—N Cokic, W Doppler, P Hlatky, C Koelblinger, C Raith, C Zölss; Royal Perth Hospital, Australia (81)—S Dimmitt, R Gharbi, G Hankey, A Maden, B P Mwipatayi, K Sieunarine, A Tan, G Turner, A Wesseldine; University of Western Australia, Fremantle Hospital, Australia (2)-T M E Davis, P E Norman; Minsk Regional Clinical Hospital, Belarus (12)—P Audzei, I Davidovski, D Dedul, A Hetsiuk, S Kornievich; Peking Union Medical College Hospital, China (6)-J Gao, Y-G Huang, G Jing, H Li, Y-J Li, B Liu, C-W Liu, J-D Wu, W Ye, C-H Yu; Klinicka Bolnica Osijek, Croatia (20)—T Ban, K Buljan, K Candrlic, D Dapic, M Ilijasevic, T Istvanic, B Kovac, S Kvolik, V Lehner, K Pinotic; University Hospital "Sestre Milosrdnice”, Croatia (12)—N Hudorović, Ž Ivanec, I Lovričević, B Mazul-Sunko, Z Novotny, D De Syo, V Vuković; Hospital Na Homolce, Czech Republic (95)—O Biebl, L Dolecek, C El Samman, H Kalasova, V Kubricht, P Matous, P Michalek, P Sedivy, M Stajnrt, M Stern, M Svec P Vitasek, J Vrzal, K Weiss; IKEM, Czech Republic (47)—L Janousek, E Kieslichova, V Mazarova, P Piza, P Vychodil; VFN, Czech Republic (29)—V Dulovcova, J Fiksa, J Hruby, M Maresch, M Mathias, D Rubes, P Tosenovsky, T Vidim; Regional Hospital Havlickuv Brod, Czech Republic (24)-M Henzl, J Riman, Z Ziegler; Faculty Hospital of Ostrava-Poruba, Czech Republic (19)—P Drabek, T Hrbac, S Reguli, J Stigler; Fakultni Nemocnice Olomouc, Czech Republic (15) - P Bachleda, P Drac, M Hudecek, J Koutna, D Sanak, P Utikal; St Anne's Faculty Hospital, Czech Republic (11)—D Goldemund, Z Gregor, J Pavlikova, J Podlaha, M Privara, R Staffa, R Vlachovsky; Nemocnice České Budějovice a.s., Czech Republic (8)—L Barankova, V Chlouba, J Fiedler, P Prazak, V Priban, A Wierer; Tartu University Hospital, Estonia (95) - T Ellervee, H Järve, A Sell, P Taba; North Estonia Regional Hospital, Estonia (9)—A Idla, V Kolbassov, S Kullamaa, 
T Paavel; Georgian Centre of Angiology and Vascular Surgery, Georgia (4)—N Abramishvili, M Bokuchava, N Kachapuridze, K Kipiani, K Papashvili, N Pargalava; J W Goethe-University-Medical Centre, Germany (76) — F Adili, A Dietz, G Neidhart, G Nentwig, T Schmitz-Rixen, O M Sitzer; Diakonissen-Stiftungs-Krankenhaus, Germany (19)—M Beno, M Essink-Hassels, K Lander, G Ruemenapf; Asklepios Klinik Wandsbek, Germany (10)—P Breuer, R Heldt, G Melichar, J Rieper; Klinikum rechts der Isar der Technischen Universität München, Germany (6)-H H Eckstein, H Poppert, G Schneider; The Red Cross Hospital of Athens, Greece (26) - V Andrikopoulos, A Angel, K Bakogiannis, M Dermitzaki, P Georgakis, C Lioupis, D Maras, K G Moulakakis, G Sfyroeras; Baranya Megyei Korhaz, Hungary (78)—E Arato, Z Gyevnar, P Hardi, G Kasza, L Kollar, G Menyhei, E Pal, L Sinay, Z Verzar, E Volgyi; Barzilai Medical Centre, Israel (21)—S S Elmakias, E Harah, K Kristal, D Lebi, Y Leonty, D Levy, R Milo, B Yoffe; Ospedale S Paolo - Università degli Studi di Milano, Italy (102)—M Bissi, B Cappellini, T Cassamali, L Corino, T Denkewitz, G Ghilardi, N Massetto, P Di Mauro, C Tommasino; Azienda Ospedaliera San Camillo-Forlanini, Italy (78)—R Bartolucci, V Buffa, F M Corsi, E D'Avino, F Di Cesare, L Di Pirro, A Lappa, S Luzzi, G Maritati, A Menichetti, F Nesi, A Pannone, P Picozzi, G Pogany, G Rabitti, L Severi; Azienda Ospedaliera Universitaria Senese, Italy (71)—R Avella, P Biandolino, P P Giomarelli, M R Monfregola, G Palasciano, V Peccianti, D Pieragalli, C Setacci, F Setacci, P Sirignano; Istituto Ortopedico Galeazzi, Italy (52) - M Bordoni, V Casadei, M Cugnasca, A De Troia, L Geremia, P Guffanti, G Lo Guercio, M V Maniaci, Mauri, A Morbidelli; Ospedale Cannizzaro, Italy (46)-A Aletta, E Costanzo, G D'Arrigo, F Di Stefano, A Lomeo, S Maugeri, M C Monea, G Scardavilli, A Scolaro; San Salvatore Hospital, Italy (40)—P Aloisi, A Ciccozzi, M Manno, A Marrelli, C Martinazzo, A Mastromarino, C Petrassi, A Piroli, C Spartera, M Ventura; Università Cattolica del Sacro Cuore - Campobasso, Italy (34)-F Alessandrini, C Carissimi, E M Centritto, G Cinelli, C De Filippo, G Liberatoscioli, P Modugno, M Rossi; Università Studi di Palermo, Italy (29)—M T Attanzio, G Bajardi, M Bellisi, P Machi, S Salemi, G Savettieri; Catholic University of Sacred Heart, "A Gemelli", Italy (27) - M A Crea, V di Lazzaro, A Ferrante, S Guarneri, R Manni, F Snider, C Stefanuto; Mauriziano Hospital, Italy (24)—G Berardi, A Bianchi, M Comis, P Cumbo, M Fadde, E Ferrero, M Ferri, A Filardo, A Gaggiano, M Ganzaroli, C Labate, D Maggio, G Mennuti, S Minicucci, A Musso, F Nessi, M Pasquino, L Perretta, S Piazza, C Verdecchia, A Viazzo; Ospedale Umberto Parini di Aosta, Italy (24)—A Antico, E Battan, M Ciarlo, G Giardini, G Luca Iob, C Marinello, D Piccolo; Ospedale Sant'Eugenio, Italy (19)—R Bove, T Castrucci, A Lorido, S Sammarco; Azienda Ospedaliera San Martino, Italy (16)-B Bruzzone, D Cannata, P Colotto, C Finocchi, N Giudici, S Mambrini, R Mazzei, D Palombo, A Pellegrino, N Rousas, A Viacava; Azienda Ospedaliera Villa Scassi, Italy (8)—D Ermirio, D Faga, G Simoni; "La Sapienza” University, Italy (7)-F Benedetti-Valentini, R Gabrielli, R Garofano, B Gossetti, R Guerricchio, L Irace, G Lenzi; Stradins University Hospital, Latvia (31)—M Gedins, K Kisis, D Krievins, I Krustina, E Lietuvietis, M Malina, N Morlata, J Rits, S Thor; Kliniska Universitates Slimnica "Gailezers", Latvia (17) - P Ivanova, I Kikule, V Liepa, A Ligers, N Stengrevica, N Vnukova, V Zvirgzdins; Medisch Spectrum Twente, Netherlands (24)—P J A M Brouwers, R H Geelkerken, A Stam, M A M Simon; Ikazia Hospital, Netherlands (10)—P T den Hoed, M Oltmans, H Rettig, H F Veen, D Zuidgeest; Medical University of Lublin, Poland (7)—M Feldo, J Kęsik, W Kobusiewicz, D Łatkiewicz, W Myślinski, S Przywara, P Terlecki, J Wroński, T Zubilewicz; Hospital S João, Portugal (7)—G Alfonso, E Azevedo, R de Albuquerque, A Mansilha; KKUH, Saudi Arabia (10)-M Al-Salman, A K Aldaif, T A Alnasr, A A El Dawlatly, A Elkayali, H M Rabee; National Institute for Cardiovascular Diseases, Slovakia (164)—E Chudikova, I Chudá, T Dulka, Z Goldenberg, P Lofaj, M Pavlikova, M Pisar, V Šefranek, R Slyško, J Tomka, Z Tóthová, Z Zita; Hospital Universitari de Bellvitge, Spain (19)-M A Cairols, E Iborra, M Mercadal, F Rubio; Hospital Sabadell Corporacio Parc Tauli, Spain (7)—D Canovas, L Cobo, A Gimenez-Gaibar, E Gonzalez, B Gonzalo, N Guilera, J Hospedales, M J Laso, J Perez, T Solanich; Sahlgrenska University Hospital, Sweden (111)—M Hensater, L Karlström, L Kjällman, L Rosengren; Sodersjukhuset, Sweden (10)—C-A Ewaldsson, P Gillgren, T-B Käll,
P Konrad, M Lindkvist, L Nilsson, R Takolander, E von Zweigbergk. Siyami Ersek Thoracic and Cardiovascular Surgery Clinic, Turkey (104)—B Cinar, T Coruh, E Kurc, D Ozsoy, M Sargin, K Tutkavul, I Yekeler; Istanbul Universitesi Istanbul Tip Fakultesi, Turkey (20) - M Aksoy, S Bahar, M Kurtoglu; Trakya University Medical School, Turkey (8)—C Arar, S Canbaz, Y Çelik, T Ege, S Ketencǐler, H Sunar, S Ünal; Ankara University Ibn-i Sina Hospital, Department of General Sugery, Turkey (4)-I Asik, U Bengisun, C Koksoy, N Yucemen; The General Infirmary at Leeds, UK (268)-J Bamford, D C Berridge, A R Bodenham, L Caldicott, J Cooper, M Cross, H Ford, R Fuller, F Gamlin, M Gough, M J Gough, S Homer-Vanniasinkum, S Howell, P Kent, A Lumb, A I D Mavor, D J A Scott, M Shah, P Wanklyn; Royal United Hospital Bath NHS Trust, UK (256)—J S Budd, M Horrocks, P McAteer, L Shaw; Royal Glamorgan General Hospital, UK (120)—R Dewar, M H Lewis, C Potter, H Richards, R Roberts, E Townsend, A Wagle, P Woodford; Stirling Royal Infirmary, UK (117)—G Hall, R Holdsworth, M Macleod, L Michels, P A G Sandercock, C Sudlow, C P Warlow, A Woods; Royal Lancaster Infirmary, UK (113)—J S Abraham, M Bukhari, A Bush, J Calvey, I Chadwick, K Krishnaprasad, T Oldham, M Tomlinson, A Vickers, D Wilson, P Wilson; Worcestershire Royal Hospital, UK (83)—S Greystone, E C Grocott, W Hayes, S Haynes, C Jenkins, D Jenkins, W Moore, I Nyamekye, P Overstall, S Riseboro, H Williams; Addenbrooke's Hospital, UK (76)—J Boyle, D Duane, M Gaunt, P J Kirkpatrick, P Martin, J E Risdall, N Scurrah, C L Turner, K Varty; North Bristol NHS Trust, Southmead Hospital, UK (55)—I T Ferguson, S Horsfall, D C Mitchell, S Robinson; Southampton General Hospital, UK (54)—J Frankel, G E Morris, M Phillips, A Sansome, D J Sparkes, J Williams; Royal Bournemouth Hospital, UK (53)—W Ashton, S Baker, M Clark, S G Darke, R Dunnill, M Hargreaves, D Jenkinson, C Thomson, N White, L D Wijesinghe; Arrowe Park Hospital, UK (50)-P Bapat, J A Barrett, S D Blair, R Chandrasekar, G Lawrence, D Lowe, G Sangster, M Smith, M Van Miert; Hillingdon Hospital, UK (46)—S K Das, O Malik, M Nel, W Rakowicz; Guy's and St Thomas' Hospital, UK (40)-M Aukett, M Carmichael, A Colchester, P R Taylor, C Wood; The Ayr Hospital, UK (39)—A Ageed, S J Boom, S Ghosh, J Godfrey, J Hewitt-Gray, I McDiarmid, S Yousif, A Ziarkowski; Pinderfields General Hospital, UK (32)-A Al-Din, M Carpenter, K Ch'ng, P J Curley, R Davey, B Henderson, J F Hossain, C D Irvine, L Loizou, A Main, A Stanners; Belfast City Hospital, UK (25)-T Muldoon, C V Soong, I Wiggam; Norfolk and Norwich University Hospital, UK (25)-M P Armon, M Burrows, L Holmes, A K Metcalf, D Nunn; Hull Royal Infirmary, UK (22)-A Abdul-Hamid, B Akomalafe, J Bryce, I Chetter, A Samaan; The John Radcliffe Hospital, UK (18)—D Briley, J Collin, C Darby, M Dobson, P Foex, C Grange, A Handa, L Hands, H E Higham, J MT Perkins, P M Rothwell, J Sear, M Stoneham; Royal Free Hospital, UK (17)—G Hamilton, C Judge, P Morris-Vincent, M Pegg, L A Wilson; Huddersfield Royal Infirmary, UK (17)—M I Aldoori, B E A Dafalla, N Kumar; Dumfries and Galloway Royal Infirmary, UK (14)_I F C Hay, P Jefferson, I Muir, W Peel, J Rutherford, J Sathianathan, S Wight, D Williams, W Wrathall; Aberdeen Royal Infirmary, UK (12) - P Bachoo, J Brittenden, C Counsell, R Patey, J Read; Countess of Chester Hospital, UK (8) - L de Cossart, S K Dimitri, P Edwards, N Fergusson, P Jameson, J Somauroo, V Taylor; The Royal Oldham Hospital, UK (8) - P D Aravindan, I Brocklehurst, S Mirza, R N Namushi, T O Oshodi, D Ruff, S A Solomon, J Vassallo; Royal Bolton Hospital, UK (8)-M Egbe, G Halstead, M Onwudike, A Putland; Royal Blackburn Hospital, UK (7)—N Roberts, R A Salaman, D Watson; Bristol Royal Infirmary, UK (6)—S Caine, J Day, P Lamont, P J Murphy, F Smith; The Freeman Hospital, UK (6) - K Beacham, P J Dorman, D Lambert, H Rodgers; Watford General Hospital, UK (6)—D Collas, S Sarin, J Shah; Kent and Canterbury Hospital, UK (6) - H S Baht, J Banks, L Cowie, G Gunathilagan, D Hargroves, R Insall, D G Smithard; Doncaster Royal Infirmary, UK (5)—D K Chadha, W R Pillay, J Rashid, J Sayles; Lewisham University Hospital, UK (4)—S Hill, G Lawton, C M Lloyd, A Marsh; Northern General Hospital, UK (3)—G Clarke, R J Lonsdale, G Venables; Blackpool, Fylde and Wyre Hospitals NHS Trust, UK (3)-R Cross, B Lord, J McIlmoyle, H Y Osman, J Robinson; Royal Cornwall Hospital, UK (2)—H Chant, A Mate, D Sim, P Upton; St Mary's Hospital, UK (1)—D Thomas, J H Wolfe; University Hospital of 
South Manchester, UK (1)—C McCollum, P O'Neill; Central Clinical Hospital N8, Ukraine (20)—V Bernatsky, L Bondar, A Karpenko, M Mamonova, N Muz, V Yavorsky.

\section{References}

1 Rothwell PM, Eliasziw M, Gutnikov SA, et al, for the Carotid Endarterectomy Trialists' Collaboration. Analysis of pooled data from the randomised controlled trials of endarterectomy for symptomatic carotid stenosis. Lancet 2003; 361: 107-16.

2 Rothwell PM, Eliasziw M, Gutnikov SA, Warlow CP, Barnett HJ, for the Carotid Endarterectomy Trialists' Collaboration. Endarterectomy for symptomatic carotid stenosis in relation to clinical subgroups and timing of surgery. Lancet 2004; 363: 915-24.

3 Halliday A, Mansfield A, Marro J, et al, MRC Asymptomatic Carotid Surgery Trial (ACST) Collaborative Group. Prevention of disabling and fatal strokes by successful carotid endarterectomy in patients without recent neurological symptoms: randomised controlled trial. Lancet 2004; 363: 1491-502.

4 Warlow C, Sudlow C, Dennis M, Wardlaw J, Sandercock P. Stroke. Lancet 2003; 362: 1211-24.

5 Rerkasem K, Bond R, Rothwell PM. Local versus general anaesthesia for carotid endarterectomy. Cochrane Database of Syst Rev 2004, 2: CD000126.

6 Rodgers A, Walker N, Schug S, et al. Reduction of postoperative mortality and morbidity with epidural or spinal anaesthesia: results from overview of randomised trials. BMJ 2000; 321: 1493.

7 Gough MJ, Bodenham A, Horrocks M, et al. GALA: an internationa multicentre randomised trial comparing general anaesthesia versus local anaesthesia for carotid surgery. Trials 2008, 9: 28.
8 Rothwell PM, Warlow CP, for the European Carotid Surgery Trialists' Collaborative Group. Prediction of benefit from carotid endarterectomy in individual patients: a risk-modelling study. Lancet 1999; 353: 2105-10.

9 Altman DG, Machin D, Bryant TN, Gardner MJ, eds. Statistics with Confidence, 2nd edn. London: BMJ Books, 2000.

10 McCleary AJ, Dearden NM, Dickson DH, Watson A, Gough MJ The differing effects of regional and general anaesthesia on cerebral metabolism during carotid endarterectomy. Eur J Vasc Endovasc Surg 1996; 12: 173-81.

11 Anonymous. Which anaesthetic technique? Bandolier 2001. http:// www.jr2.ox.ac.uk/bandolier (accessed Nov 17, 2008).

12 Rigg JR, Jamrozik K, Myles PS, et al, for the MASTER anaesthesia trial study group. Epidural anaesthesia and analgesia and outcome of major surgery: a randomised trial. Lancet 2002; 359: $1276-82$.

13 Desborough JP. The stress response to trauma and surgery. Br J Anaesth 2000; 85: 109-17.

14 Bond R, Rerkasem K, AbuRahma AF, Naylor AR, Rothwell PM Patch angioplasty versus primary closure for carotid endarterectomy. Cochrane Database of Syst Rev 2004; 2: CD000160.

15 Hakl M, Michalek P, Sevcík P, Pavlíková J, Stern M. Regional anaesthesia for carotid endarterectomy: an audit over 10 years. Br J Anaesth 2007; 99: 415-20.

16 Pandit JJ, Satya-Krishna R, Gration P. Superficial or deep cervical plexus block for carotid endarterectomy: a systematic review of complications. Br J Anaesth 2007; 99: 159-69. 